ORIGINAL ARTICLE

\title{
Effects of enzyme replacement therapy on pain and health related quality of life in patients with Fabry disease: data from FOS (Fabry Outcome Survey)
}

\author{
B Hoffmann, A Garcia de Lorenzo, A Mehta, M Beck, U Widmer, R Ricci, on behalf of the FOS \\ European Investigators
}

J Med Genet 2005;42:247-252. doi: 10.1136/jmg.2004.025791

See end of article for authors' affiliations

.....................

Correspondence to: Dr B Hoffmann, Department for General Pediatrics, University Children's Hospital, Heinrich Heine University Düsseldorf, Moorenstr. 5, D-40225 Düsseldorf, Germany; hoffmann@ med.uni-duesseldorf.de

Received 27 July 2004 Revised version received 1 October 2004 Accepted for publication 5 October 2004
Background: Fabry disease is an $\mathrm{X}$ linked lysosomal storage disease caused by deficiency of the lysosomal enzyme $\alpha$-galactosidase A. This leads to accumulation of globotriaosylceramide in nearly all tissues, including the blood vessels, kidney, myocardium, and nervous system. Symptoms often begin in childhood and include acroparaesthesia, with burning or tingling pain that spreads from the extremities to more proximal sites.

Aims: This study set out to evaluate pain and its influence on quality of life in patients with Fabry disease receiving enzyme replacement therapy (ERT) with agalsidase alfa.

Methods: Data were obtained from the Fabry Outcome Survey. Pain was measured using the Brief Pain Inventory (BPI), and health-related quality of life (HRQoL) was documented with the European Quality of Life Questionnaire (EQ-5D).

Results: The mean (SD) score for "pain at its worst" on the BPI prior to ERT was 5.1 (2.7). One year after commencement of ERT, this had improved by 0.5 , and improved by a further 0.6 after 2 years $(p<0.05)$. Similar statistically significant improvements were seen for "pain on average" and "pain now" after 2 years of ERT. The mean HRQoL utility score prior to ERT was 0.66 (0.32). After 12 months of treatment with agalsidase alfa, this had improved to $0.74(0.26 ; \mathrm{p}<0.05)$; this improvement was maintained after 2 years.

Conclusions: ERT with agalsidase alfa significantly reduces pain and improves quality of life in patients with Fabry disease.
$\mathrm{F}$ abry disease (Anderson-Fabry disease; OMIM 301 500) is a metabolic disorder with $\mathrm{X}$ linked inheritance and an estimated incidence of $1: 40 \quad 000$ to $1: 117000$ in hemizygous males. ${ }^{2}{ }^{2}$ It is caused by deficiency of the lysosomal enzyme $\alpha$-galactosidase $\mathrm{A}$ and leads to the accumulation of the enzyme substrate, globotriaosylceramide $\left(G_{3}\right)$. With increasing age, $\mathrm{Gb}_{3}$ accumulates throughout the body, and deposition can be found in nearly all tissues.

The clinical onset of Fabry disease is typically during childhood or adolescence, with signs and symptoms including acroparaesthesia, diminished sweating, and gastrointestinal complaints. ${ }^{3}$ A high percentage of patients with Fabry disease also suffers from pain resulting from small fibre neuropathy, ${ }^{3-6}$ which is known from other conditions to have an impact on quality of life (QoL).$^{7-9}$ Ultimately, the storage of $\mathrm{Gb}_{3}$ leads to reduced organ function, including renal insufficiency, which may progress to end stage renal disease. ${ }^{10-12}$ Patients often develop hypertrophic cardiomyopathy and valvular abnormalities, and may suffer myocardial infarction. ${ }^{13-16}$ In addition, transient ischaemic attacks or stroke are common, especially in older patients with Fabry disease. ${ }^{17}{ }^{18}$ In untreated hemizygous males, life expectancy is reduced; there is a steep decline in survival after the age of 35 years, with death occurring within the fifth decade of life for the majority of patients. ${ }^{3}$

Until recently, women with a deleterious mutation in the gene for $\alpha$-galactosidase A were not considered to be patients, but were regarded merely as carriers. In the last few years, however, several studies have shown that women are also affected by Fabry disease, although usually less severely than men. ${ }^{19-25}$ These findings can be explained by the concept of random X inactivation..$^{26} 27$ In females, one X chromosome in each cell is randomly switched "on" and one is switched "off". Thus, heterozygote females are mosaics, with different cells in the body expressing either the normal or the disease carrying gene. ${ }^{27}$

Since 2001, it has been possible to replace the enzyme missing in patients with Fabry disease by infusion of enzyme preparations. Within the European Union, two products are approved for the treatment of Fabry disease: agalsidase alfa (Replagal; TKT Europe-5S) and agalsidase beta (Fabrazyme; Genzyme Corp.). Enzyme replacement therapy (ERT) with agalsidase alfa has been shown to be effective in improving renal pathology and cardiac function, and in reducing the severity of neuropathic pain and improving pain related QoL. ${ }^{28}$

QoL measures have become increasingly important in recent years. They are useful for understanding the impact both of a disease and of its treatment on a patient's functioning and wellbeing..$^{29}$ Thus, they allow measurement and quantification of the outcome of healthcare interventions. ${ }^{31}$ Only a few authors have specifically evaluated the effects of Fabry disease on QoL. ${ }^{32}$ These evaluations, carried out in male patients, have shown that health related QoL (HRQoL) is impaired compared with the general population, and is more severely impaired than in patients with another lysosomal storage disease, Gaucher disease. ${ }^{32}$ However, neither of these studies included female

Abbreviations: BPI, Brief Pain Inventory; ERT, enzyme replacement therapy; EQ-5D, European Quality of Life Questionnaire; FOS, Fabry Outcome Survey; HRQoL, health related quality of life; QoL, quality of life; WHO, World Health Organization 
patients and, importantly, the effect of ERT on QoL has not been evaluated.

This paper aims to describe QoL and pain related QoL in patients enrolled in the Fabry Outcome Survey (FOS), the most comprehensive database of patients with Fabry disease, both before and during ERT with agalsidase alfa.

\section{METHODS}

FOS is a European database for patients with Fabry disease. At the time of this analysis (March 2004), 545 patients (264 female and 281 male) were registered on the database. Of these, 314 patients $(58 \%)$ were receiving intravenous ERT with agalsidase alfa every 2 weeks at a dose of $0.2 \mathrm{mg} / \mathrm{kg}$. Data are collected anonymously and entered by physicians or specialist nurses into the database. The FOS database has been approved by the ethics review boards of all participating institutions, and all patients gave written informed consent. The FOS database and its properties have been described previously. ${ }^{25}$

\section{Evaluating quality of life in FOS}

According to the World Health Organization (WHO) Quality of Life Working Group, QoL is defined as an individual's perception of their position in life. This has to be seen in the context of the culture and value system in which the person lives. Furthermore, it must be related to the individual's goals, expectations, standards, and concerns. ${ }^{34}$ To evaluate an item of such complexity would appear unfeasible. The WHO definition of health as "a state of complete physical, mental, and social wellbeing and not merely the absence of disease" has similar practical limitations. ${ }^{35}$ The concept of HRQoL has therefore been established. Instruments that aim to measure HRQoL are designed solely to measure QoL with respect to an individual's health state.

There are several instruments available to measure HRQoL. One of these is the European Quality of Life questionnaire (Euro-QOL; EQ-5D), which covers five dimensions: mobility, pain/discomfort, self care, anxiety/depression, and usual activities. Each dimension comprises three levels (no problems, some/moderate problems, extreme problems). The questionnaire is designed for self completion and validated for different countries within Europe, and also in the USA and other countries worldwide. It is a non-disease specific instrument and generates a generic cardinal index of health. ${ }^{36-38}$ An EQ-5D score of 1 means "full health" and a score of 0 is equivalent to "death". By calculation, it is also possible to get a health state "worse than death" $(<0))^{39}$ Representative EQ-5D data from a "normal" population are available for comparison. ${ }^{38}$

\section{Evaluating pain in FOS}

The Brief Pain Inventory (BPI) contains a series of questions relating to pain and its interference with life. Each question can be answered by circling a number between 0 and 10 . According to the scoring of "pain at its worst" the patients can be assigned to one of three groups: a pain score of $1-4$ is ascribed to mild pain, a score of 5-6 is defined as moderate pain, and a score of $7-10$ represents severe pain..$^{40}$ Like the EQ-5D, the BPI is validated for different languages. It was developed to measure pain and its influence on life. ${ }^{41}$ Although the BPI was primarily designed to measure pain in patients with cancer, it has become widely accepted in different healthcare settings where the impact of pain has to be recorded. ${ }^{40-45}$ Finally, the BPI has been shown to be responsive to interventional treatments. ${ }^{41}$

\section{Data sample and statistics}

The data presented here result from evaluations at baseline and after a mean (SD) of 12 (3) months and 24 (3) months of treatment with agalsidase alfa. Baseline values are taken as the value reported up to 6 months preceding or up to 3 months after the onset of ERT with agalsidase alfa.

In FOS, patients are asked to fill out both the EQ-5D and BPI questionnaires regularly. For this evaluation, we excluded children enrolled in FOS, as reliable reference data for the EQ-5D and BPI are only available for adults.

Wilcoxon's rank sum test, Student's $t$ test and Spearman's rank correlation were used where appropriate. Numbers are presented as mean (SD).

\section{RESULTS \\ HRQoL}

Prior to ERT, the mean EQ-5D utility score was $0.66(0.32)$ ( $n=120 ; 47$ women, 73 men), with no difference observed in utility score between sexes. The EQ-5D utility scores were significantly lower than those reported for the normal UK population, matched for age and sex $(\mathrm{p}<0.05$; table 1$) .^{38}$

Information was available from 59 patients ( 20 women, 39 men) prior to ERT and after l year of treatment. These patients had a mean (SD) EQ-5D score of 0.64 (0.32) at baseline. After 12 months of treatment with agalsidase alfa,

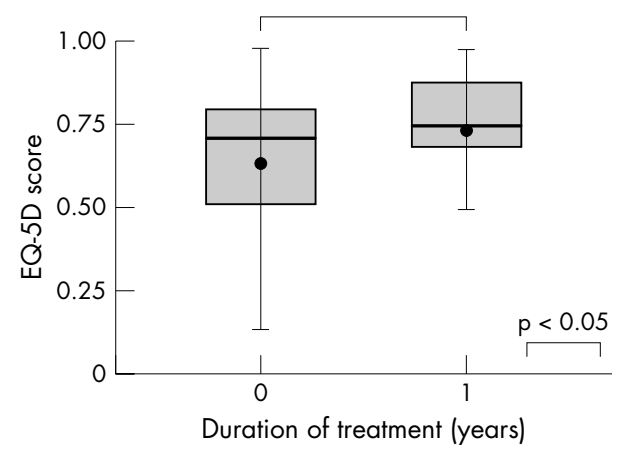

Figure 1 Improvement in health related quality of life after 1 year of treatment with agalsidase alfa in patients with Fabry disease $(n=59 ; 20$ women, 39 men) measured using the European Quality of Life Questionnaire (EQ-5D).

Table 1 Median and mean European Quality of Life Questionnaire (EQ-5D) utility scores at baseline in 120 patients with Fabry disease compared with data from the normal UK population $^{38}$

\begin{tabular}{|c|c|c|c|c|}
\hline & \multicolumn{2}{|l|}{ EQ-5D utility score } & \multicolumn{2}{|c|}{ Difference from normal UK population data } \\
\hline & $\begin{array}{l}\text { Median (10th to } \\
90 \text { th percentile) }\end{array}$ & Mean (SD) & $\begin{array}{l}\text { Median (10th to } \\
90 \text { th percentile) }\end{array}$ & Mean (SD) \\
\hline $\begin{array}{l}\text { All patients }(n=120) \\
\text { Women }(n=47) \\
\text { Men }(n=73)\end{array}$ & $\begin{array}{l}0.76(0.13 \text { to } 1.00) \\
0.80(0.12 \text { to } 1.00) \\
0.76(0.14 \text { to } 1.00)\end{array}$ & $\begin{array}{l}0.66(0.32) \\
0.67(0.34) \\
0.66(0.31)\end{array}$ & $\begin{array}{l}-0.15(-0.73 \text { to } 0.11) \\
-0.11(-0.72 \text { to } 0.18) \\
-0.15(-0.75 \text { to } 0.09)\end{array}$ & $\begin{array}{l}-0.23(0.32)^{*} \\
-0.19(0.34)^{*} \\
-0.25(0.32)^{*}\end{array}$ \\
\hline
\end{tabular}




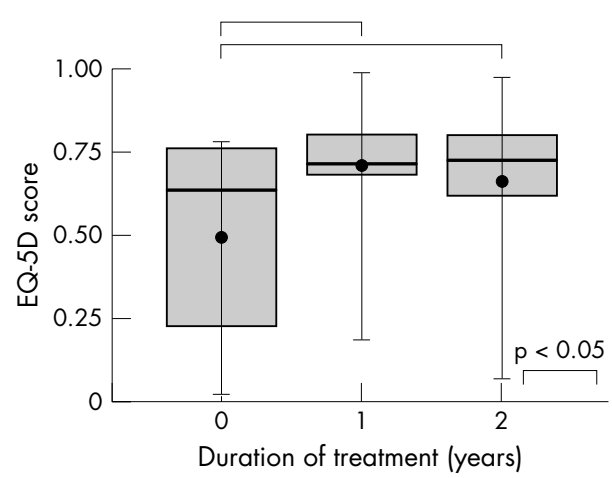

Figure 2 Improvement in health related quality of life after 1 and 2 years of treatment with agalsidase alfa in patients with Fabry disease ( $n=28 ; 4$ women, 24 men) measured using the European Quality of Life Questionnaire (EQ-5D).

this had improved significantly $(0.74$ (0.26), $\mathrm{p}<0.05$; fig 1$)$ and no longer differed from the reference data for the normal UK population. No differences were found between men and women (data not shown). On the pain/discomfort dimension of the EQ-5D, 14 patients reported no problems, 37 reported moderate problems, and 8 reported extreme problems at baseline. An improvement on this scale occurred after 1 year of treatment with agalsidase alfa, with 21 patients reporting no problems, 36 reporting moderate problems, and 2 reporting extreme problems.

For 28 patients (four women, 24 men), longitudinal data were available for two consecutive years of ERT. The mean (SD) EQ-5D score prior to ERT in these patients was 0.50 (0.32). The significant improvement seen after 1 year was maintained after 2 years of treatment with agalsidase alfa in this group (fig 2), and, likewise, the EQ-5D score after 2 years did not differ significantly from the scores for the UK reference population.

On the pain/discomfort dimension of the EQ-5D, l patient had reported no problems at baseline, 21 had reported moderate problems, and 6 had reported extreme problems. Following 2 years of treatment with agalsidase alfa, 9 of these patients now reported no problems, 18 reported moderate problems, and only 1 reported extreme problems.

\section{Pain}

BPI scores prior to the initiation of ERT with agalsidase alfa are shown in table 2. The mean BPI score for "pain at its worst" was 5.1 (2.7) and the mean score for "pain at its

\begin{tabular}{|c|c|c|}
\hline & $n$ & Mean (SD) \\
\hline \multicolumn{3}{|l|}{ BPI dimension } \\
\hline Pain at its worst & 90 & $5.1(2.7)$ \\
\hline Pain at its least & 89 & $2.1(2.5)$ \\
\hline Pain on average & 90 & $4.1(2.5)$ \\
\hline Pain now & 91 & $2.9(2.8)$ \\
\hline \multicolumn{3}{|c|}{ Interference of pain with: } \\
\hline General activity & 102 & $3.3(3.1)$ \\
\hline Mood & 103 & $3.3(3.2)$ \\
\hline Walking ability & 102 & $2.5(3.1)$ \\
\hline Normal work & 101 & $3.4(3.4)$ \\
\hline Social relations & 103 & $2.7(3.0)$ \\
\hline Sleep & 102 & $2.5(3.2)$ \\
\hline Enjoyment of life & 103 & $3.0(3.2)$ \\
\hline
\end{tabular}

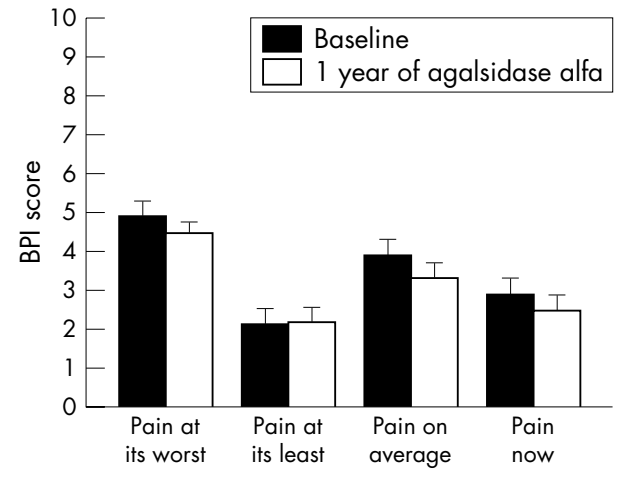

Figure 3 Improvement in Brief Pain Inventory scores after 1 year of treatment with agalsidase alfa in patients with Fabry disease $(n=41 ; 14$ women, $27 \mathrm{men})$.

least" was 2.1 (2.5). Before beginning ERT, patients reported that in the previous 24 hours pain interfered most with general activity $(3.3(3.1))$ and mood $(3.3(3.2))$, and least with walking ability $(2.5(3.1))$ and sleep (2.5 (3.2)).

After a mean duration of 12 months of ERT with agalsidase alfa, 41 patients completed the questionnaire. "Pain on average", "pain now" and "pain at its worst" had improved (mean scores had decreased by $0.6,0.4$, and 0.5 , respectively); however, this was not statistically significant. The mean value for "pain at its least" did not change (fig 3). At baseline, "pain on average" had been reported as none in 4 patients, mild in 21 , moderate in 9, and severe in 7 . Following 1 year of treatment with agalsidase alfa, "pain on average" was reported as none in 8 patients, mild in 20 , moderate in 10 and severe in 3.

The effects of 2 years of ERT with agalsidase alfa on mean BPI scores are shown in fig 4 for the 20 patients followed longitudinally over this period. Values for "pain on average" decreased by 0.7 after 1 year and by a further 0.9 after 2 years of treatment. "Pain now" decreased by 0.9 after 1 year and by a further 0.4 after 2 years of treatment. For "pain at its worst" the decrease was 0.5 during the first year and 0.6 during the second year of treatment. All these changes between baseline and 2 years were statistically significant $(\mathrm{p}<0.05$; fig 4$)$. Although the mean score for "pain at its least" decreased by 0.5 and 0.3 after 1 and 2 years, respectively, these changes were not statistically significant. At baseline, "pain on average" had been reported as mild in 10 patients, moderate in 5 , and severe in 5 . Following 2 years of treatment with agalsidase alfa, "pain on average" was

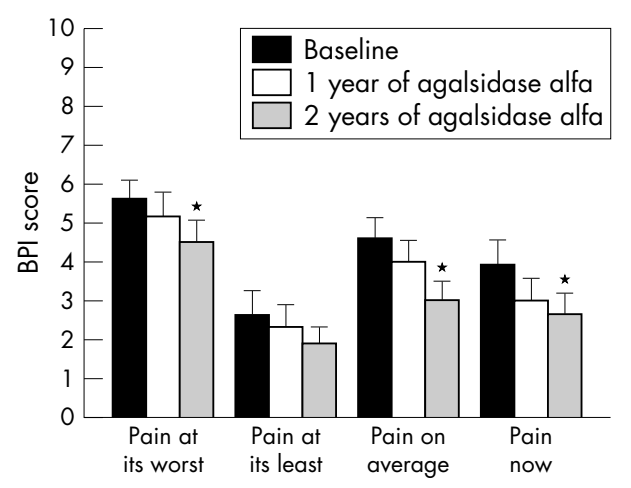

Figure 4 Improvement in Brief Pain Inventory scores after 1 and 2 years of treatment with agalsidase alfa in patients with Fabry disease ( $n=20 ; 4$ women, 16 men). ${ }^{*} p<0.05$ compared with baseline. 

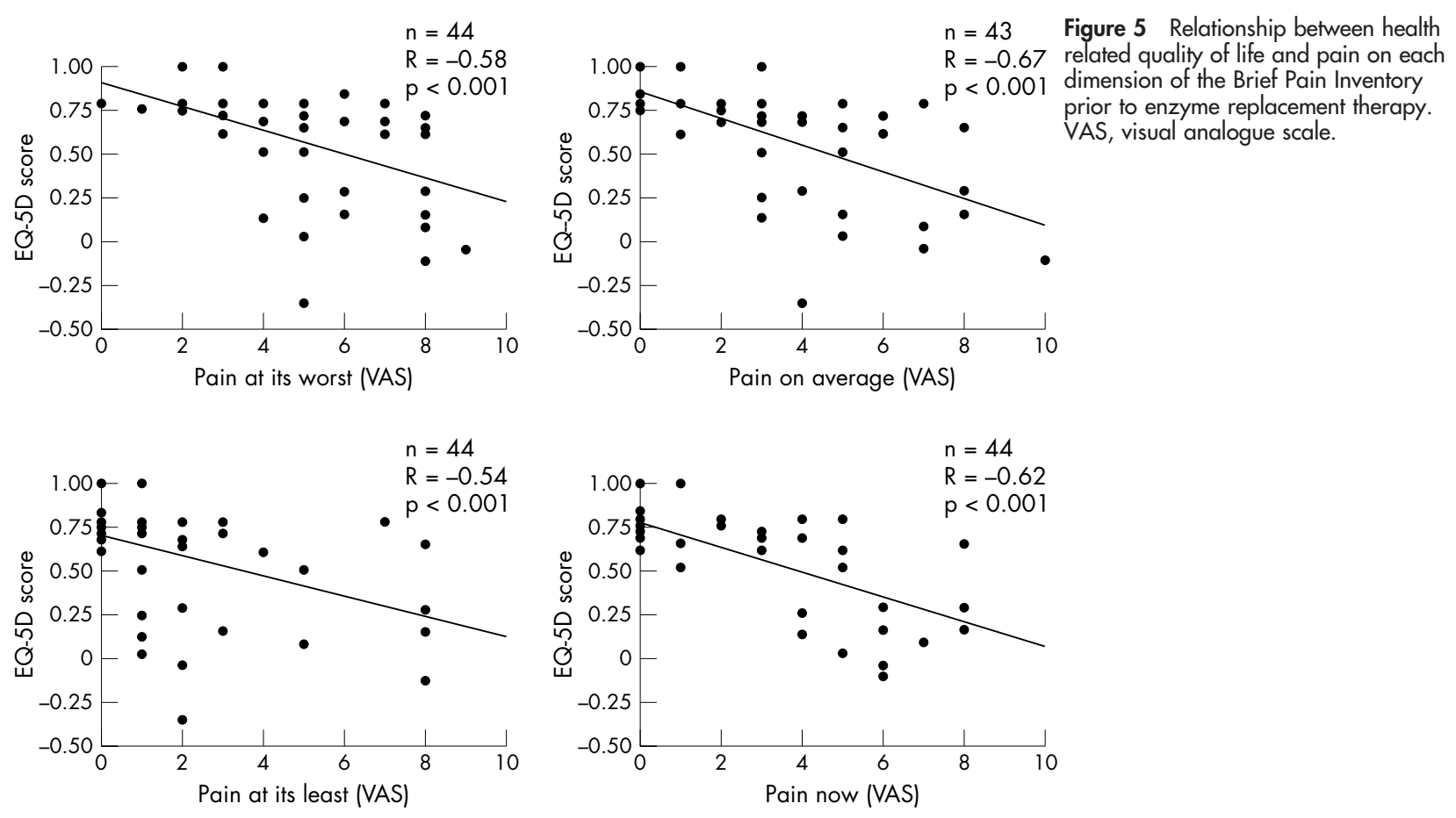

reported as none in 4 patients, mild in 12 , moderate in 3 , and severe in 1.

\section{Relationship between HRQoL and pain}

At baseline, there was a statistically significant negative correlation between the EQ-5D and all dimensions of the BPI (fig 5). There was no correlation between pain or EQ-5D score and age.

\section{DISCUSSION}

QoL is impaired in patients with Fabry disease prior to treatment with ERT. In the current study, the EQ-5D scores of patients with Fabry disease at baseline were found to be significantly decreased compared with age and sex matched control data from the UK population. Compared with other patient groups who have completed this questionnaire, patients with Fabry disease were found to score slightly worse on the EQ-5D than those who have undergone liver transplantation and women with breast cancer; ${ }^{46}{ }^{47}$ however, patients who have undergone kidney transplantation and those with lung cancer show a worse HRQoL. ${ }^{48} 49$

After 12 months of treatment with agalsidase alfa, QoL improved significantly in patients with Fabry disease, with no differences observed between men and women. Importantly, the improvement was maintained after 24 months of treatment. In contrast, EQ-5D scores decrease with age in the normal population ${ }^{38}$ and in untreated patients with Fabry disease. ${ }^{33}$

Similar to other questionnaires that generate a generic index of health states, such as the Short Form-36, the EQ-5D has some limitations. It was established to detect and to measure changes in HRQoL reported by the patient and thus does not provide an objective measure with which to detect an improvement or deterioration in health state. Therefore, improvement of HRQoL does not imply improvement in an individual's physical health state, but an improvement in the patient's perception of their health state. Several reports have described improvements in different organ systems under
ERT, ${ }^{6}{ }^{1721}$ but it is unclear whether these are reflected by improvements in the patient's perception of health. Measures of HRQoL, or so called "patient reported outcomes", have become useful and important tools in evaluating healthcare interventions. ${ }^{29}{ }^{30}$ Such tools are likely to be important in evaluating therapy in Fabry disease, as there are no biomarkers of disease severity in this condition.

Before treatment with agalsidase alfa, the pain reported by patients with Fabry disease was, on average, categorised as moderate (mean (SD) BPI score, 5.1 (2.7)); however, the term "moderate pain" is unlikely to reflect the whole burden of the pain experienced by patients with Fabry disease. The statistically significant negative correlation between pain and the EQ-5D score illustrates that this moderate pain affects HRQoL and thus has a major impact in patients with Fabry disease.

Scores for "pain on average", "pain now", and "pain at its worst" on the BPI improved, but not significantly, following 1 year of treatment with agalsidase alfa. However, after 2 years of treatment, there was a significant improvement in all three scores.

Several questionnaires, in particular the BPI, have been accepted as useful tools for evaluating pain. Nevertheless, there may still be concerns about using such purely subjective instruments. A more objective measure of pain evaluation is quantitative sensory testing, as used by Dütsch et al to evaluate heat pain perception in patients with Fabry disease. ${ }^{4}$ This group presented 25 stimuli of different intensity up to $49^{\circ} \mathrm{C}$ to patients with Fabry disease and asked the patients to grade their response to the stimulus on a visual analogue scale ranging from 0 (no discomfort or pain) to 10 (most discomfort or pain). Their findings clearly indicated impaired $\mathrm{A} \delta$, and, to a lesser extent, C nerve fibre function in patients with Fabry disease. These findings could explain the lack of improvement of neuropathic pain in some patients in our cohort, as it is unlikely that pain perception via structurally damaged nerve fibres can be improved. Additionally, these findings provide support for early ERT in order to prevent irreversible structural damage to nerve tissue. 


\section{CONCLUSION}

Fabry disease has a major effect on QoL. Patients with Fabry disease show significantly lower EQ-5D scores compared with normative population data. ERT with agalsidase alfa (Replagal) significantly improves QoL in patients after 1 year of treatment. These promising results were sustained after 2 years of ERT. Pain is a major contributor to the decreased QoL in Fabry disease, and "pain on average", "pain now", and "pain at its worst", as measured by the BPI, were all significantly reduced after 2 years of ERT with agalsidase alfa.

\section{ACKNOWLEDGEMENTS}

The authors very much appreciate the support of all patients enrolled in FOS and are very much obliged to all those who entered data into the database. The following investigators submitted data from their patients. Austria: Bodamer O, Hauser A-C, Kleinert J, and SunderPlassmann G (Vienna), and Kotanko P, Kroepfl T, and Plecko B (Graz); Belgium: Clerbaux G, Georges B, Nassogne MC, and Pirson Y (Brussels), Dehout F, Roland D, and Van Maldergem L (Charleroi), and De Smet K, and Eyskens F (Middelheim). Czech Republic: Bultas J, Karetová D, Linhart A, Lubanda J-C, and Magage S (Prague). France: Choukroun G (Amien), Berthelot J (Anger), Benziane S (Cambrais), Khau Van Kien A (Dijon), Dussol B (Marseille), Jaeger P (Nice) and Germain D and Lidove O (Paris), Jaussaud R (Reims); Germany: von Arnim-Baas A, and Hennermann J (Berlin), Neumann HPH (Freiburg), Das A, and Illsinger S (Hannover), Beck M, DelgadoSanchez S, Kampmann C, Kim KS, Schwarting A, Tremmel H, and Whybra C (Mainz), Hoffmann B, and Koletzko B (Munich), and Böttcher T, and Rolfs A (Rostock). Italy: Gabrielli O, and Salvatori IF (Ancona), Borsini W, and Buchner S (Florence), Parini R, Ravaglia R, and Santus S (Milan), Di Vito R, and Gasbarri C (Ortona), Burlina A, and Tognana G (Padova), Antuzzi D, Castorina M, Di Lillo M, Feriozzi S, and Ricci R (Rome). Norway: Bindoff LA, Bostad LH, Grant AL, Haugen OH, Hirth A, Houge G, Kaarbøe Ø, Lægreid LM, Neckelmann G, Svarstad E, Thune TJ, and Tøndel C (Bergen), and Skarbøvik A, and Tafjord A-B (Ålesund). Spain: Barba MA (Albacete), Gómez Huertas E, and Herrera J (Asturias), Ara J, Bonal J, Larrousse E, and Pintos G (Badalona), Ballarin J, Torra R, Torras J, and Torregrosa V (Barcelona), González J (Cadiz), Garcia M, Herrera C, Martin I, and Rodriguez J (Huelva), Barbado FJ, Garcia-Consuegra J, Garcia de Lorenzo A, and López M (Madrid), Paniagua J (Ponferrada), Hernández S (Linares), Fernández V, and León A (Santiago),, andreu J, León JA, and Maya E (Seville), Febrer I, and Perez García A (Valencia), and Rivera A (Vigo). Switzerland: Ferrari P, and Vogt B (Bern), Barbey F, and Theytaz J (Lausanne), and Schulthess G, Walter K, and Widmer U (Zurich). UK: Cox TM, Deegan P, Ramaswami U, and Wright $\mathrm{N}$ (Cambridge), and Burns A, Elliott J, Elliott PM, Evans S, Ginsberg L, Hughes D, Mehta A, Milligan A, Orteu C, Richfield L, and Shah J (London).

\section{Authors' affiliations}

B Hoffmann, University Children's Hospital, Heinrich Heine University, Düsseldorf, Germany

A G de Lorenzo, Hospital Universitario, La Paz, Madrid, Spain

A Mehta, University College London, London, UK

M Beck, University of Mainz, Mainz, Germany

U Widmer, University of Zurich, Zurich, Switzerland

R Ricci, Institute of Clinical Pediatrics, UCSC, Rome, Italy

The FOS database is under the independent control of the FOS European board. Data collection and analysis in FOS are supported by TKT Europe-5S, Danderyd, Sweden. The sponsor had no role in the interpretation of data or writing of this report.

Competing interests: none declared

\section{REFERENCES}

1 Meikle PJ, Hopwood JJ, Clague AE, Carey WF. Prevalence of lysosomal storage disorders. JAMA 1999:281:249-54.

2 Peters FP, Vermeulen A, Kho TL. anderson-Fabry's disease: alphagalactosidase deficiency. Lancet 2001;357:138-40.

3 MacDermot KD, Holmes A, Miners AH. anderson-Fabry disease: clinical manifestations, and impact of disease in a cohort of 98 hemizygous males. J Med Genet 2001:38:750-60.

4 Dutsch M, Marthol H, Stemper B, Brys M, Haendl T, Hilz MJ. Small fiber dysfunction predominates in Fabry neuropathy. $J$ Clin Neurophysiol 2002; 19:575-86.
5 Ries $M$, Mengel E, Kutschke G, Kim KS, Birklein F, Krummenauer F, Beck M. Use of gabapentin to reduce chronic neuropathic pain in Fabry disease. $J$ Inherit Metab Dis 2003;26:413-14.

6 Schiffmann R, Floeter MK, Dambrosia JM. Enzyme replacement therapy improves peripheral nerve, and sweat function in Fabry disease. Muscle Nerve 2003;28:703-10

7 Gallagher RM. Low back pain, health status, and quality of life in older adults: challenge, and opportunity. Pain Med 2003;4:305-7.

8 Phillips $\mathrm{CJ}$. [Pain management: health economics, and quality of life considerations]. Drugs 2003;63:47-50.

9 Nicholson B, Verma S. Comorbidities in chronic neuropathic pain. Pain Med 2004;5(suppl 1):S9-27.

10 Grunfeld JP, Lidove O, Joly D, Barbey F. Renal disease in Fabry patients. $J$ Inherit Metab Dis 2001;24(suppl 2):71-4.

11 Branton MH, Schiffmann R, Sabnis SG, Murray GJ, Quirk JM, Altarescu G, Goldfarb L, Brady RO, Balow JE, Austin HA III, Kopp JB. Natural history of Fabry renal disease: influence of alpha-galactosidase $A$ activity, and genetic mutations on clinical course. Medicine (Baltimore) 2002:81:122-38.

12 Obrador GT, Ojo A, Thadhani R. End-stage renal disease in patients with Fabry disease. J Am Soc Nephrol 2002;13(suppl 2):S144-6.

13 Beer G, Reinecke P, Gabbert HE, Hort W, Kuhn H. Fabry disease in patients with hypertrophic cardiomyopathy (HCM). Z Kardiol 2002;91:992-1002.

14 Kampmann C, Baehner F, Ries M, Beck M. Cardiac involvement in, andersonFabry disease. J Am Soc Nephrol 2002;13(suppl 2):S147-9.

15 Kampmann C, Wiethoff CM, Perrot A, Beck M, Dietz R, Osterziel KJ. The heart in, anderson Fabry disease. Z Kardiol 2002;91:786-95.

16 Linhart A, Magage S, Palecek T, Bultas J. Cardiac involvement in Fabry disease. Acta Paediatr Suppl 2002;91:15-20.

17 Brady RO, Schiffmann R. Clinical features of, and recent advances in therapy for Fabry disease. JAMA 2000;284:2771-5.

18 Schiffmann R. Natural history of Fabry disease in males: preliminary observations. J Inherit Metab Dis 2001;24(suppl 2):15-17.

19 Whybra C, Kampmann C, Willers I, Davies J, Winchester B, Kriegsmann J, Bruhl K, Gal A, Bunge S, Beck M. anderson-Fabry disease: clinical manifestations of disease in female heterozygotes. J Inherit Metab Dis 2001; 24:715-24

20 Whybra C, Wendrich K, Ries M, Gal A, Beck M. Clinical manifestation in female Fabry disease patients. Contrib Nephrol 2001b;136:245-50.

21 Baehner F, Kampmann C, Whybra C, Miebach E, Wiethoff CM, Beck M. Enzyme replacement therapy in heterozygous females with Fabry disease: results of a phase IIIB study. J Inherit Metab Dis 2003;26:617-27.

22 Guffon N. Clinical presentation in female patients with Fabry disease. J Med Genet 2003:40:e38

23 Morrone A, Cavicchi C, Bardelli T, Antuzzi D, Parini R, Di Rocco M, Feriozzi S, Gabrielli O, Barone R, Pistone G, Spisni C, Ricci R, Zammarchi E. Fabry disease: molecular studies in Italian patients, and $\mathrm{X}$ inactivation analysis in manifesting carriers. J Med Genet 2003;40:e103.

24 Rodriguez-Mari A, Coll MJ, Chabas A. Molecular analysis in Fabry disease in Spain: fifteen novel GLA mutations, and identification of a homozygous female. Hum Mutat 2003;22:258

25 Mehta A, Ricci R, Widmer U, Dehout F, Garcia de Lorenzo A, Kampmann C, Linhart A, Sunder-Plassmann G, Ries M, Beck M. Fabry disease defined: baseline clinical manifestations of 366 patients in the Fabry Outcome Survey. Eur J Clin Invest 2004;34:236-42.

26 Lyon MF. Gene action in the X-chromosome of the mouse (Mus musculus L.). Naturwissenschaften 1961;190:372-3.

27 Lyon MF. X-chromosome inactivation, and human genetic disease. Acta Paediatr Suppl 2002;91:107-12

28 Schiffmann R, Kopp JB, Austin HA, Sabnis S, Moore DF, Weibel T, Balow JE, Brady RO. Enzyme replacement therapy in Fabry disease: a randomized controlled trial. JAMA 2001:285:2743-9.

29 Bergner M. Quality of life, health status, and clinical research. Med Care 1989;27:S1 48-56.

30 Santanello NC, Baker D, Cappelleri JC, Copley-Merriman K, DeMarinis R, Gagnon JP, Hsuan A, Jackson J, Mahmoud R, Miller D, Morgan M, Osterhaus J, Tilson H, Willke R. Regulatory issues for health-related quality of life - PhRMA Health Outcomes Committee workshop, 1999. Value Health 2002;5:14-25.

31 Hennessy CH, Moriarty DG, Zack MM, Scherr PA, Brackbill R. Measuring health-related quality of life for public health surveillance. Public Health Rep 1994; 109:665-72.

32 Gold KF, Pastores GM, Botteman MF, Yeh JM, Sweeney S, Aliski W, Pashos CL. Quality of life of patients with Fabry disease. Qual Life Res 2002;11:317-27.

33 Miners AH, Holmes A, Sherr L, Jenkinson C, MacDermot KD. Assessment of health-related quality-of-life in males with, anderson Fabry disease before therapeutic intervention. Qual Life Res 2002;11:127-33.

34 World Health Organization. World Health Organization Quality of Life assessment (WHOQOL). Position paper from the World Health Organization. Soc Sci Med 1995;41:1403-9.

35 World Health Organization. World Health Organization constitution. Basic documents, Geneva, Switzerland, 1948.

36 van Agt HM, Essink-Bot ML, Krabbe PF, Bonsel GJ. Test-retest reliability of health state valuations collected with the EuroQol questionnaire. Soc Sci Med 1994;39:1537-44.

37 Brooks R. Quality of life measures. Crit Care Med 1996;24:1769.

38 Kind P, Hardman G, Macran S. UK population norms for EQ-5D, Discussion paper. York: Centre for Health Economics, 1999:172

39 Macran S, Kind P. "Death", and the valuation of health-related quality of life. Med Care 2001;39:217-27. 
40 Cleeland CS. Pain assessment: the advantages of using pain scales in lysosomal storage diseases. Acta Paediatr Suppl 2002;91:43-7.

41 Cleeland CS, Ryan KM. Pain assessment: global use of the Brief Pain Inventory. Ann Acad Med Singapore 1994;23:129-38.

42 Breitbart W, Rosenfeld B, Passik S, Kaim M, Funesti-Esch J, Stein K. A comparison of pain report, and adequacy of analgesic therapy in ambulatory AIDS patients with, and without a history of substance abuse. Pain 1997;72:235-43

43 Sculco AD, Paup DC, Fernhall B, Sculco MJ. Effects of aerobic exercise on low back pain patients in treatment. Spine J 2001;1:95-101.

44 Davison SN. Pain in hemodialysis patients: prevalence, cause, severity, and management. Am J Kidney Dis 2003;42:1239-47.

45 Tan G, Jensen MP, Thornby Jl, Shanti BF. Validation of the brief pain inventory for chronic nonmalignant pain. J Pain 2004;5:133-7.
46 Bryan S, Ratcliffe J, Neuberger JM, Burroughs AK, Gunson BK, Buxton MJ. Health-related quality of life following liver transplantation. Qual Life Res 1998;7:115-20.

47 Conner-Spady B, Cumming C, Nabholtz JM, Jacobs P, Stewart D. Responsiveness of the EuroQol in breast cancer patients undergoing high dose chemotherapy. Qual Life Res 2001;10:479-86.

48 Trippoli S, Vaiani M, Lucioni C, Messori A. Quality of life, and utility in patients with non-small cell lung cancer. Quality-of-life Study Group of the Master 2 Project in Pharmacoeconomics. Pharmacoeconomics $2001 ; 19: 855-63$

49 Cleemput I, Kesteloot K, De Geest S, Dobbels F, Vanrenterghem Y. Health professionals' perceptions of health status after renal transplantation: a comparison with transplantation candidates' expectations. Transplantation 2003;76:176-82. 